\title{
Casein Kinase 2
}

National Cancer Institute

\section{Source}

National Cancer Institute. Casein Kinase 2. NCI Thesaurus. Code C107559.

A serine/threonine kinase that is a tetrameric protein complex comprised of 2 catalytic alpha subunits and 2 regulatory beta subunits. This kinase complex is involved in the modulation of many cellular processes, including cell cycle progression and apoptosis regulation. 